\title{
Two Woody Scented Oils from the Amazonian Forest
}

\author{
Eduardo Mattoso, ${ }^{a, b}$ Charlene S. dos Anjos, ${ }^{\circledR a}$ Lauro Barata $^{c}$ and Anita J. Marsaioli ${ }^{\circledR} *, a$ \\ ${ }^{a}$ Laboratório de Biocatálise e Produtos Naturais, Instituto de Química, \\ Universidade Estadual de Campinas, Rua Josué de Castro, $s / n$, Cidade Universitária, \\ Bloco A5, sala A5-103, 13083-861 Campinas-SP, Brazil \\ ${ }^{b}$ Laboratório de Produtos Naturais, Kairós Fitoquímicos Campinas, \\ Rua Lauro Vannucci, 1020, 13087-548 Campinas-SP, Brazil \\ ${ }^{c}$ Laboratório de Pesquisa \& Desenvolvimento de Produtos Naturais Bioativo, \\ Departamento de Química, Universidade Federal do Oeste do Pará, Unidade Tapajós, \\ Rua Vera Paz, s/n, Bairro Salé, 68040-255 Santarém-PA, Brazil
}

\begin{abstract}
The essential oils from Aniba parviflora and the balsam from Protium rubrum, which are two woody scented Amazonian species, were analyzed by gas chromatography-mass spectrometry (GC-MS), ${ }^{1} \mathrm{H}$ and ${ }^{13} \mathrm{C}$ nuclear magnetic resonance (NMR). GC-MS analysis revealed the presence of unknown constituents. These compounds were then isolated, analyzed and characterized by NMR. Both substances presented distinct woody notes that contributed to the bulk woody character of the crude oils.
\end{abstract}

Keywords: Aniba parviflora, Protium rubrum, $\beta$-phellandrene, $\Delta^{4(4 \mathrm{a})}-\left(2 R^{*}, 8 R^{*}, 8 \mathrm{a} S^{*}\right)$-eremophilen9-ol, thymol derivatives

\section{Introduction}

Brazil is one of world's richest countries in terms of biodiversity, but it has made only a small contribution of new natural raw materials to the flavors and fragrances $(F \& F)$ industry. Despite the growing number of published articles, the aromatic ingredients available from Brazilian plants in the F\&F market are almost the same as 50 years ago: rosewood, copaiba and tonka beans. ${ }^{1}$

With the aim of improving this situation, the chemical composition and potential application in the F\&F market were examined for an essential oil and a balsam from the Amazon region after an evaluation by a perfumer.

The essential oil of Aniba parviflora (Meissner) Mez is produced by a species belonging to Lauraceae, a family possessing approximately 52 genera and 1900 species that are well distributed in the tropics. ${ }^{2}$ Examples of Lauraceae essential oils that are consumed worldwide include bay (Laurus nobilis), cinnamon (Cinnamomum zeylanicum and Cinnamomum cassia), and camphor (Cinnamomum camphora). The genus Aniba

*e-mail: anita@iqm.unicamp.br

Editor handled this article: Paulo Cezar Vieira is restricted to the Neotropical region, and rosewood (Aniba rosaeodora) is its most famous species.

Aniba parviflora is a small tree similar to rosewood, and it is often misclassified as a young A. rosaeodora; it is native to the central eastern Brazilian Amazon and occurs naturally near small rivers in non-flooded areas. The wounded bark is yellow in A. parviflora and reddish in rosewood, and there is a remarkable olfactory difference between them. Two A. parviflora experimental plantations that exist for commercial purposes can be found near the city of Belém, and these were made by mistake 15 years ago when the researchers thought they were planting rosewood. A third plantation is located between the Amazon and Tapajos rivers at the experimental campus of Amazon Federal Rural University (UFRA), and it is approximately 30 years old and occupies 5 hectares of a forest regeneration experimental station founded by FAO (Food and Agriculture Organization of United Nation). Plant material from this 30-year-old plantation was used for this study.

The other woody scent comes from Protium rubrum, known as "Cuatrec", which is a rare Burseraceae distributed in Brazil, Peru and Colombia. ${ }^{3}$ The Burseraceae family has approximately 20 genera and 600 species that are well distributed in the tropics. ${ }^{4}$ This family is well known for its triterpenic resins, a bark exudate, such as myrrh, olibanum 
and frankincense. In Brazil, this kind of resin is very common in the Amazon region and on the Bahia coast, where people use it to add perfume to their homes by burning it, or to seal boat hull cracks. Unlike other species of Protium trees, this P. rubrum has a balsam instead of a resin. Similar to Copaiba trees, the balsam is collected by utilizing a deep hole in the tree bark. This balsam does not have a traditional use and was discovered when farmers were cutting down an area for cassava cultivation in Silves, AM.

\section{Experimental}

\section{Reagents and solvents}

Unless stated otherwise, all chemicals were purchased from Sigma-Aldrich (São Paulo, Brazil), and the solvents were of high-performance liquid chromatography (HPLC) grade (São Paulo, Brazil).

\section{Plant material}

Thin branches and leaves of A. parviflora were collected (year 2000) in the Curuá-una Experimental Field of the Wood Technology Center (CTM) of UFRA. The material $(5200 \mathrm{~kg})$ was collected for 3 days and was transported by river to the town of Santarem in a $24 \mathrm{~h}$ trip, where it was steam distilled in a $3000 \mathrm{~L}$ iron tank fed by an antique iron retort operating with a vapor flow of $30 \mathrm{~kg} \mathrm{~h} \mathrm{~m}^{3}$. The distillation tank could process $700 \mathrm{~kg}$ with each operation; therefore 3 days were required to perform the 8 necessary operations. Water came from an artesian well and went directly to the retort. The plant material was ground before undergoing distillation, and it was distilled for four hours at atmospheric pressure. The oil was treated with sodium sulfate before chromatographic analyses.

The Protium rubrum balsam was collected at the São Pedro community, Silves, in the central Amazon (year 2000). A tree was cut while an area was cleared for a cassava plantation, and the balsam was released from it in abundance. It was collected in a polyethylene bottle, brought to the city and transferred to a glass bottle. Before analysis, the balsam was treated with sodium sulfate and filtered.

\section{Compound isolation}

Sesquiterpenoid AF105 (later identified as eremophilen9-ol, 1), which is responsible for some woody and floral notes, is present at $5 \%$ in A. parviflora essential crude oil. For isolation, $10 \mathrm{~g}$ of the essential oil was fractionally distilled with $10 \mathrm{~g}$ of paraffin (Synth, São Paulo, Brazil) to increase the thermal capacity of the system. The mixture was heated under a vacuum in an oil bath. The monoterpenes and nonoxygenated sesquiterpenes were distilled using up to $80 \%$ of the total oil. The cooled residue was then extracted 3 times with ethanol. This procedure increased the concentration of the woody scented target compound from 5 to $25 \%$. Then, regular fractioning was performed using a silica column (Acros, São Paulo, Brazil, 0.035-0.070 mm particles with $6 \mathrm{~nm}$ pore diameter) followed by silica coated with $10 \% \mathrm{AgNO}_{3}$ (Acros, São Paulo, Brazil). Both columns were eluted with hexane that contained increasing amounts of ethyl acetate. This procedure yielded compound $\mathbf{1}$ with 97\% purity. Previous attempts without the fractionation/ distillation step resulted in a contamination of oxygenated monoterpene after two chromatographic separations.

Compounds 5 and 6, isolated from $P$. rubrum, were obtained by single silica column fractionation.

\section{Synthesis of the valerianol compound}

To obtain the valerianol substrate, two synthetic steps were necessary.

\section{(i) Trifluoroacetylation of valencene}

Two grams of commercial Acros brand valencene (São Paulo, Brazil) were solubilized in $20 \mathrm{~mL}$ of hexane. The mixture was homogenized by adding $1.6 \mathrm{~g}$ of trifluoroacetic acid. Immediately the solution turned from colorless to violet.

The mixture remained under magnetic stirring at about $50{ }^{\circ} \mathrm{C}$ for $120 \mathrm{~min}$. Due to the low yield verified by thin layer chromatography (TLC), the reaction was kept for another $24 \mathrm{~h}$ at room temperature. The mixture was washed with saturated sodium bicarbonate solution $\left(\mathrm{NaHCO}_{3}\right)$, extracted with ethyl acetate and dried over anhydrous sodium sulfate $\left(\mathrm{Na}_{2} \mathrm{SO}_{4}\right)$. The solvent was initially evaporated in a rotary evaporator and then in a $\mathrm{N}_{2}$ gas line. The product generated, valerianyl trifluoroacetate, was isolated by column chromatography.

(ii) Hydrolysis of valerianyl trifluoroacetate

Valerianyl trifluoroacetate $(31.8 \mathrm{mg})$ and $4 \mathrm{~mL}$ of solvent were added as follows: $2.4 \mathrm{~mL}$ of tetrahydrofuran, $0.8 \mathrm{~mL}$ of methanol, $0.8 \mathrm{~mL}$ of water. After homogenization, $16.8 \mathrm{mg}$ of hydrated lithium hydroxide $\left(\mathrm{LiOH} \cdot \mathrm{H}_{2} \mathrm{O}\right)$ was added. The mixture was kept under magnetic stirring in ambient temperature for $2 \mathrm{~h}$.

It was then washed with $10 \%$ hydrochloric acid solution, extracted with ethyl acetate and dried over sodium sulfate. The solvent was removed in an analogous manner to the previous reaction. The alcohol formed, valerianol, was isolated by chromatography on column. 


\section{Gas chromatography-mass spectrometry (GC-MS) analysis}

Both the A. parviflora oil and P. rubrum balsam were analyzed on a Hewlett-Packard gas chromatograph Model 6890 coupled to a Hewlett-Packard mass spectrometer (MS) Model 5973 (Agilent, São Paulo, Brazil) equipped with an HP5 column (30 $\mathrm{m} \times 0.25 \mathrm{~mm}, 0.25 \mu \mathrm{m}$ film thickness) programmed from 50 to $190{ }^{\circ} \mathrm{C}$ at $3{ }^{\circ} \mathrm{C} \mathrm{min}^{-1}$ with a 5 min hold. The carrier gas was helium at $1 \mathrm{~mL} \mathrm{~min}^{-1}$; split mode injection (1:30) and an injector temperature of $200{ }^{\circ} \mathrm{C}$ were used. The MS ran in electron impact mode at $70 \mathrm{eV}$, the electron multiplier was set to $1800 \mathrm{~V}$ and the ion source temperature was $280^{\circ} \mathrm{C}$. Mass spectral data were acquired in the scan mode from $m / z, 40$ to 500 a.m.u.

${ }^{1} \mathrm{H}$ and ${ }^{13} \mathrm{C}$ nuclear magnetic resonance (NMR) analysis

The isolated compounds underwent ${ }^{1} \mathrm{H},{ }^{13} \mathrm{C}$, and 1 and
2D NMR experiments with Bruker Avance III equipment (Eisenhutweg, Germany). The spectra were acquired with a Varian INOVA-500 $\left(\mathrm{B}_{0}=11.7 \mathrm{~T}\right)$ operating at $499.88 \mathrm{MHz}$ for ${ }^{1} \mathrm{H}$ and $125.71 \mathrm{MHz}$ for ${ }^{13} \mathrm{C}$, using $5 \mathrm{~mm}$ probes for direct and indirect detections. The material was dissolved in $\mathrm{CDCl}_{3}$ at concentrations varying from 2 to $20 \mathrm{mg} \mathrm{mL}^{-1}$. The residual chloroform present in deuterochloroform (7.27 ppm) was used as the internal reference.

\section{Results and Discussion}

The steam distillation of A. parviflora leaves yielded $0.10 \%$ of an essential oil, which was analyzed by GC-MS (Table 1), revealing a nonidentified compound named AF105 that was present at ca. $5 \%$ with a calculated retention index of 1626.

With the chemical composition analysis of essential oil, it was possible to observe that main compounds were

Table 1. GC-MS results of A. parviflora essential oil. The isolated compound AF 105 appears in bold

\begin{tabular}{|c|c|c|c|c|}
\hline No. & Compound $^{5}$ & KI lit ${ }^{\mathrm{a}}$ & $\mathrm{KI} \exp ^{\mathrm{b}}$ & $\%^{\mathrm{c}}$ \\
\hline 1 & $\alpha$-thuyene & 931 & 930 & 0.31 \\
\hline 2 & $\alpha$-pinene & 939 & 935 & 2.86 \\
\hline 3 & camphene & 953 & 947 & 0.80 \\
\hline 4 & sabinene & 976 & 971 & 0.21 \\
\hline 5 & $\beta$-pinene & 980 & 973 & 1.52 \\
\hline 6 & myrcene & 991 & 989 & 1.70 \\
\hline 7 & $\alpha$-phellandrene & 1005 & 1001 & 7.98 \\
\hline 8 & $\delta$-3-carene & 1011 & 1006 & 0.15 \\
\hline 9 & $\alpha$-terpinene & 1018 & 1012 & 0.18 \\
\hline 10 & p-cymene & 1026 & 1020 & 4.02 \\
\hline 11 & $\beta$-phellandrene & 1031 & 1024 & 15.12 \\
\hline 12 & eucalyptol & 1033 & 1026 & 0.86 \\
\hline 13 & $Z$-beta-ocimene & 1040 & 1034 & 0.16 \\
\hline 14 & $E$-beta-ocimene & 1050 & 1044 & 3.81 \\
\hline 15 & $\gamma$-terpinene & 1062 & 1053 & 0.31 \\
\hline 16 & terpinolene & 1088 & 1082 & 0.34 \\
\hline 17 & linalool & 1098 & 1097 & 14.60 \\
\hline 18 & borneol & 1165 & 1160 & 0.16 \\
\hline 19 & terpine-4-ol & 1177 & 1172 & 0.25 \\
\hline 20 & $\alpha$-terpineol & 1189 & 1186 & 0.90 \\
\hline 21 & $\alpha$-cubebene & 1351 & 1345 & 0.43 \\
\hline 22 & $\alpha$-ylangene & 1372 & 1366 & 0.14 \\
\hline 23 & isoledene & 1373 & 1368 & 0.11 \\
\hline 24 & $\alpha$-copaene & 1376 & 1370 & 0.49 \\
\hline 25 & $\beta$-elemene & 1391 & 1387 & 0.52 \\
\hline 26 & $\alpha$-gurjunene & 1409 & 1404 & 0.16 \\
\hline 27 & $\beta$-caryophyllene & 1418 & 1413 & 6.05 \\
\hline 28 & $\beta$-gurjunene & 1432 & 1423 & 0.20 \\
\hline 29 & not identified & - & 1428 & 0.12 \\
\hline 30 & aromadendrene & 1439 & 1433 & 1.79 \\
\hline 31 & not identified & - & 1439 & 0.36 \\
\hline 32 & $\alpha$-humulene & 1454 & 1447 & 0.79 \\
\hline 33 & alloaromadendrene & 1461 & 1455 & 0.60 \\
\hline 34 & $\gamma$-muurolene & 1477 & 1472 & 0.70 \\
\hline
\end{tabular}

\begin{tabular}{|c|c|c|c|c|}
\hline No. & Compound $^{5}$ & $\mathrm{KI} \mathrm{lit}^{\mathrm{a}}$ & $\mathrm{KI} \exp ^{\mathrm{b}}$ & $\%^{\mathrm{c}}$ \\
\hline 35 & germacrene D & 1480 & 1475 & 0.97 \\
\hline 36 & $\beta$-selinene & 1485 & 1480 & 1.23 \\
\hline 37 & not identified & - & 1482 & 0.17 \\
\hline 38 & bicyclogermacrene & 1494 & 1492 & 6.75 \\
\hline 40 & $(E, E)$ - $\alpha$-farnesene & 1508 & 1507 & 0.53 \\
\hline 41 & $\gamma$-cadinene & 1513 & 1509 & 0.28 \\
\hline 42 & $\delta$-cadinene & 1524 & 1520 & 0.80 \\
\hline 43 & elemol & 1549 & 1546 & 0.39 \\
\hline 44 & germacrene B & 1556 & 1551 & 0.81 \\
\hline 45 & not identified & - & 1554 & 0.11 \\
\hline 46 & $E$-nerolidol & 1564 & 1562 & 0.47 \\
\hline 47 & not identified & - & 1566 & 0.14 \\
\hline 48 & spathulenol & 1576 & 1573 & 4.13 \\
\hline 49 & caryophyllene oxide & 1581 & 1577 & 2.16 \\
\hline 50 & viridiflorol & 1590 & 1586 & 0.36 \\
\hline 51 & not identified & - & 1588 & 0.37 \\
\hline 52 & guaiol & 1595 & 1593 & 0.49 \\
\hline 53 & not identified & - & 1596 & 0.45 \\
\hline 54 & not identified & - & 1602 & 0.25 \\
\hline 55 & not identified & - & 1607 & 0.14 \\
\hline 56 & not identified & - & 1613 & 0.27 \\
\hline 57 & not identified & - & 1617 & 0.33 \\
\hline 58 & AF 105 & 1626 & 1626 & 5.05 \\
\hline 59 & iso-spathulenol & 1639 & 1634 & 0.59 \\
\hline 60 & not identified & & 1638 & 0.30 \\
\hline 61 & $\beta$-eudesmol & 1649 & 1644 & 1.03 \\
\hline 62 & $\alpha$-eudesmol & 1652 & 1648 & 1.27 \\
\hline 63 & not identified & - & 1653 & 0.16 \\
\hline 64 & not identified & - & 1661 & 0.37 \\
\hline 66 & benzyl benzoate & 1762 & 1761 & 0.12 \\
\hline \multicolumn{4}{|c|}{ Total recovered } & 99.19 \\
\hline
\end{tabular}


terpenoids $\beta$-phellandrene (15.12\%), linalool (14.60\%), $\alpha$-phellandrene (7.98\%), bicyclogermacrene $(6.75 \%)$ and $\beta$-caryophyllene $(6.05 \%)$, corroborating with Xavier etal. ${ }^{6}$ and Oliveira et al., ${ }^{7}$ who report the presence of these compounds in essential oil of A. parviflora with similar percentages.

To evaluate the contribution of AF 105, an unknown constituent, to the entire oil odor, a sniff test was set up with two columns of equal length attached to the same injector with one end linked to the mass detector and the other used for sniffing experiments. The odor of AF105 was therefore classified as having a woody-floral note with green touches.

The next step was to isolate the compound and determine its chemical structure by 1D and 2D NMR in a Varian probe ( ${ }^{1} \mathrm{HNMR},{ }^{13} \mathrm{CNMR}$, heteronuclear single quantum correlation spectroscopy (HSQC), heteronuclear multiple bond correlation spectroscopy (HMBC), correlation spectroscopy (COSY)). By comparing the ${ }^{13} \mathrm{CNMR}$ chemical shifts with the other eremophilane, ${ }^{8,9}$ we could conclude that this compound is identical to $\Delta^{4(4 \mathrm{aa})}-\left(2 R^{*}, 8 R^{*}, 8 \mathrm{a} S^{*}\right)$-eremophilen-9-ol or (2-[(2R*, $\left.8 R^{*}, 8 \mathrm{a} S^{*}\right)-8,8 \mathrm{a}$-dimethyl- $1,2,3,5,6,7,8,8 \mathrm{a}$-octahydronaphthalen-2-yl]-propan-2-ol), 1, which was previously isolated by Itokawa et al..$^{9}$ (Figure 1). The carbon chemical shift differences between the jinkoheremol reported by Ishihara et al. ${ }^{8}$ and $\mathbf{1}$ are probably due to diastereomers of these two compounds, which also display different optical rotations (jinkoheremol ${ }^{5}\left([\alpha]_{D}^{29}=-74.5^{\circ}, c=1.33, \mathrm{CHCl}_{3}\right.$; eremophilen-9-oll ${ }^{7}[\alpha]_{D}{ }^{29}=-14.9^{\circ}, c=0.45, \mathrm{CHCl}_{3}$; isolated compound $1[\alpha]_{D}^{22}=-6^{\circ}, c=5, \mathrm{CHCl}_{3}$ ) (Supplementary Information (SI) section).

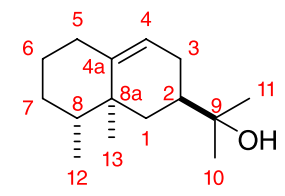

Figure 1. Structure of compound 1.

Compound 1 was then sent to a perfumer for an olfactory evaluation, and its odor was classified as a floral balsamic, which was a bottom note in the entire oil odor.

The high structural similarity between eremophilen9-ol 1 and valerianol 4, a major constituent of Valeriana officinalis essential oil,${ }^{10}$ inspired us to produce 4 to perform an olfactory comparison between these two isomers. Therefore, valencene $\mathbf{2}$ was first derivatized to valerianyl trifluoroacetate $\mathbf{3}$ in $70 \%$ by applying Mattos et al. ${ }^{11}$ methodology, which produced valerianol 4 upon hydrolysis (Figure 2).

Valerianol 4 was characterized by GC-MS, ${ }^{1} \mathrm{H}$ NMR and ${ }^{13} \mathrm{C}$ NMR and compared with data in the

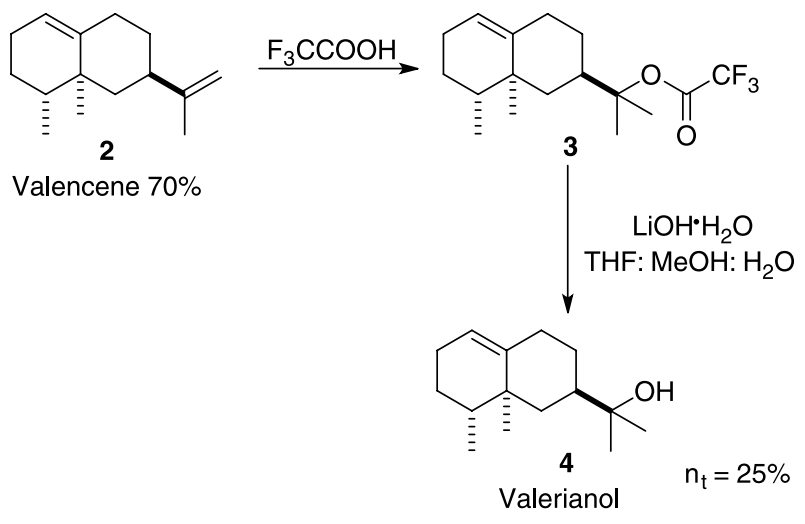

Figure 2. Synthetic route to produce valerianol from valencene.

literature. ${ }^{12}$

The olfactory comparison revealed high similarity between 1 and 4 . Eremophilen-9-ol 1 has a slightly more pronounced floral character, while valerianol $\mathbf{4}$ has a more pronounced green note.

\section{Protium rubrum}

Compounds PR192 and PR210 were isolated and identified by ${ }^{1} \mathrm{H}$ NMR and ${ }^{13} \mathrm{C}$ NMR spectra (SI section). The suggested structures are 1-isopropenyl-2,5-dimethoxy4-methylbenzene (5) and 1-isopropanol-2,5-dimethoxy4-methylbenzene (6) (Figure 3).
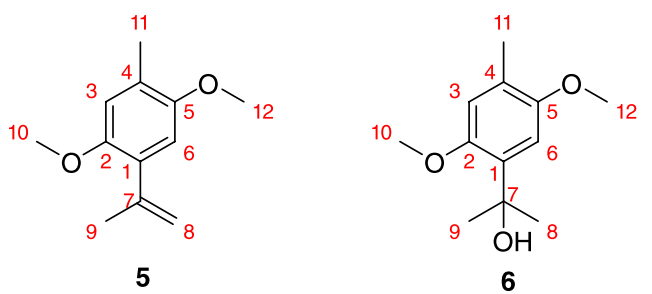

Figure 3. Structure of compounds 1-isopropenyl-2,5-dimethoxy-4-methylbenzene (5) and 1-isopropanol-2,5-dimethoxy-4-methylbenzene (6).

These molecules were also sent for an olfactory evaluation to determine their contribution to the whole oil fragrance and the olfactory difference caused by the presence of a hydroxyl group.

Compound 5 was classified as almost odorless with a very weak balsamic note, and although it is the main constituent, it has a very small contribution to the balsam fragrance. Compound $\mathbf{6}$ possesses a dry woody note that is easily identified in crude balsam. The GC-MS analysis of $P$. rubrum balsam is presented in Table 2 .

\section{Conclusions}

The structure of compound AF105 was suggested to be 2-[(2R* $\left., 8 R^{*}, 8 \mathrm{a} S^{*}\right)-8,8$ a-dimethyl-1,2,3,5,6,7,8,8a-octa- 
Table 2. Compounds identified in P. rubrum balsam by GC-MS. Isolated molecules appearing in bold

\begin{tabular}{lcccc}
\hline No. & Compound $^{5}$ & KI lit $^{\mathrm{a}}$ & $\mathrm{KI} \mathrm{exp}^{\mathrm{b}}$ & $\%^{\mathrm{c}}$ \\
\hline 1 & limonene & 1031 & 1030 & 1.84 \\
2 & $\alpha$-copaene & 1376 & 1375 & 0.77 \\
3 & cyperene & 1398 & 1401 & 0.32 \\
5 & Z-alpha-bergamotene & 1415 & 1418 & 0.65 \\
$\mathbf{6}$ & PR 192 & - & $\mathbf{1 4 3 4}$ & $\mathbf{8 4 . 1 8}$ \\
7 & not identified & - & 1440 & 2.17 \\
8 & not identified & - & 1472 & 0.30 \\
10 & not identified & - & 1503 & 0.69 \\
11 & $\beta$-bisabolene & 1509 & 1506 & 2.16 \\
12 & $Z$-gamma-bisabolene & 1515 & 1509 & 0.85 \\
$\mathbf{1 3}$ & $\quad$ PR 210 & - & $\mathbf{1 5 5 7}$ & $\mathbf{6 . 0 7}$ \\
\hline \multicolumn{4}{l}{ Total recovered } \\
a Kovats retention index in literature; ${ }^{\mathrm{b}}$ experimental Kovats retention index, \\
${ }^{\mathrm{c}}$ relative percentage of compound identified.
\end{tabular}

hydronaphthalen-2-yl]-propan-2-ol based on GC-MS and ${ }^{1} \mathrm{H}$ and ${ }^{13} \mathrm{C}$ NMR data, which were identical to the eremophilenol previously isolated from Alpinia japonica. However, this is the first time eremophilenol $\mathbf{1}$ has been isolated from a Lauraceae.

The double bond position in 1 and in 4 did not change the olfactory characteristics of these compounds.

The same analytical tools were applied to $\mathbf{5}$ and $\mathbf{6}$, revealing that for the first time these aromatic compounds were isolated from Burseraceae. Their olfactory properties were evaluated by a perfumer, and the authors believe that both essential oils have olfactory potential to be included in the perfumer's pallet.

\section{Supplementary Information}

Supplementary information $\left({ }^{1} \mathrm{H}\right.$ NMR and ${ }^{13} \mathrm{C}$ NMR spectra for compounds $\mathbf{1}, \mathbf{5}$, and $\mathbf{6}$ ) are available free of charge at http://jbcs.sbq.org.br as PDF file.

\section{Acknowledgments}

The authors would like to thank CNPq and FAPESP for support; Avive for the sample of Protium rubrum balsam;
Kairos Fitoquímicos and Givaudan do Brasil for sponsoring Eduardo Mattoso's fellowship; and Marco Carmini for support during the beginning of the work.

\section{References}

1. 2013-2017 Flavor \& Fragrance Industry Leaders, http://www. leffingwell.com/top_10.htm, accessed in September 2021.

2. Souza-Junior, F. J. C.; Luz-Moraes, D.; Pereira, F. S.; Barros, M. A.; Fernandes, L. M. P.; Queiroz, L. Y.; Maia, C. F.; Maia, J. G. S.; Fontes-Junior, E. A.; Chem. Biodiversity 2021, 18, 10.

3. Hopkins, M. J. G.; Rev. Saude Publica 2005, 56, 2175.

4. Daly, D. C. B.: A Taxonomic Revision of Protium (Burseraceae) in Eastern Amazonia and Guianas; $\mathrm{PhD}$ thesis, City University of New York, New York, USA, 1987, available at https://www. proquest.com/docview/303462480?pq-origsite $=$ gscholar\&fro mopenview=true, accessed in September 2021.

5. Adams, R. P.; Identification of Essential Oils Components by Gas Cromatography/Mass Spectroscopy, $2^{\text {nd }}$ ed.; Allured Publishing Coorporation: Carol Stream, 1995.

6. Xavier, J. K. A. M.; Maia, L.; Figueiredo, P. L. B.; Folador, A.; Ramos, A. R.; Andrade, E. H.; Maia, J. G. S.; Setzer, W. N.; Silva, J. K. R.; Molecules 2021, 26, 1914.

7. Oliveira, F. P.; Rodrigues, A. C. B. C.; Lima, E. J. S. P.; Silva, V. R.; Santos, L. S.; Anunciação, T. A.; Nogueira, M. L.; Soares, M. B. P.; Dias, R. B.; Rocha, C. A. G.; Junior, S. D.; Albuquerque, P. M.; Lima, E. S.; Gonçalves, J. F. C.; Bataglion, G. A.; Costa, E. V.; Silva, F. M. A.; Koolen, H. H. F.; Bezerra, D. P.; Chem. Biodiversity 2021, 18, e2000938.

8. Ishihara, M.; Tsuneya, T.; Uneyama, K.; Phytochemistry 1993, $33,1147$.

9. Itokawa, I.; Morita, H.; Watanabe, K.; Mirashi, S.; Itaka, Y.; Chem. Pharm. Bull. 1985, 33, 1148.

10. Jommi, G.; Krepinsky, J.; Herout, V.; Sorm, F.; Collect. Czech. Chem. Commun. 1969, 34, 593. apud Arantes, F. A.; Hanson, J. R.; Hitchcock, P. B.; Phytochemistry 1999, 52, 1063.

11. Mattos, M. C. S.; Coelho, R. B.; Sanseverino, A. M.; Synth Commun. 2004, 34, 525.

12. Arantes, S. F.; Hanson, J. R.; Hitchcock, P. B.; Phytochemistry 1999, 52, 1063. 